Int. J. Dev. Biol. 49: 1-8 (2005)

doi: $10.1387 / \mathrm{ijdb} .041908 \mathrm{ss}$

Essay

\title{
From eggs to fossils: epigenesis and transformation of species in Pander's biology
}

\author{
STÉPHANE SCHMITT* \\ REHSEIS (UMR 7596), Université Denis-Diderot, Paris, France
}

\begin{abstract}
Christian Heinnich Pander (1794-1865), a Russian scientist of German culture, is known forhis epoch-making workin embryology, as well as forhis important contributionsto palaeontology. Indeed he viewed embryonic development and the history of the earth as two aspects of one and the same essential phenomenon, namely, a perpetual metamorphosis affecting the living world on different scales. He viewed embryology as a gradual, epigenetic transformation (as opposed to preformation) with an intermediary stage, the formation of simple germ-layers. As early as 1821, he argued more generally that species themselves transform under the influence of certain environmental factors. Pander thus embodies the very close link that existed between the triumph of epigenesis and the expansion of transformist theories in the early 19th century.
\end{abstract}

KEY WORDS: Pander, germ-layers, history of embryology, epigen esis, tran sformation of species

\section{Introduction}

Christian Heinrich Pander (1794-1865) is well known for his books on the development of birds (Pander, 1817a; 1817b), work which made the victory of the theory of epigenesis upon preformationism views virtually complete. He is also and independently, famous for having described geological formations from the primary era and for having identified many fossil groups. But in his own mind these studies were both parts of one and the same field, whose object was a general phenomenon, namely the permanent metamorphosis of living beings. According to him, the development of a given individual and the gradual transformation of species in the course of earth history were two sides of this phenomenon. Even though the originality of Pander's global perspective is little appreciated today. It is important for understanding the history of biology at that time, because it demonstrates the close link which existed between the epigenetic embryology and the transformist theory from the beginning of the 19th century.

\section{Biographical sketch}

Pander was born July 24th 1794 in Riga, at that time in the Russian Empire, in a wealthy German family (on Pander's biography see Baer, 1866; Raikov, 1951, 1984; Knorre, 1973; Bullough, 1974; Churchill, 1991; Mikhailov, 1997; and the introduction in Pander, 2003). He went to Dorpat (now Tartu, in Estonia) Univer- sity in 1812 to study medicine and there met Carl Ernst von Baer (1792-1876), with whom he stroke up a friendship. But they were not satisfied with the medical program, which was mediocre. Subsequently Pander went to Germany, to complete his training in one of the prestigious universities of this country. He went first to Berlin (1814), then to Göttingen and in March 1816 he met up with Baer again in Jena. The latter had worked in Würzburg with the famous physiologist and anatomist Ignaz Döllinger (1770-1841) and he convinced his friend to follow him there. They were warmly received in the home of Döllinger, who was then looking for a student to undertake a complete description of the early chicken embryology. This task required time and money, because several hundred hen eggs and expensive artificial incubators had to be purchased and the incubation temperature had to be watched all the time by a servant. Pander, whose family was wealthy enough, accepted the position and began working. He was assisted by the draftman Eduard d'Alton (1772-1840), then famous for his beautiful monograph on the horse in two volumes (D'Alton, 1811-1816). The three men worked together for several months in close collaboration. Pander opened the eggs and made the observations, d'Alton drew from life under his supervision. Döllinger gave some advice on the operating method. The results were presented in Pander's doctoral Dissertatio in Latin (Pander, 1817a). The plates engraved by d'Alton were printed the same year, with a German text (Pander, 1817b).

But in the following years, Pander did not carry on this study and he decided to turn to comparative osteology. He travelled through-

\footnotetext{
*Address correspondence to: Dr. Stéphane Schmitt. REHSEIS (UMR 7596), Université Denis-Diderot, 2 place J ussieu, 75005 Paris, France.

Fax: +33-1-4427-8647. e-mail: stephane_schmitt@yahoo.fr
} 


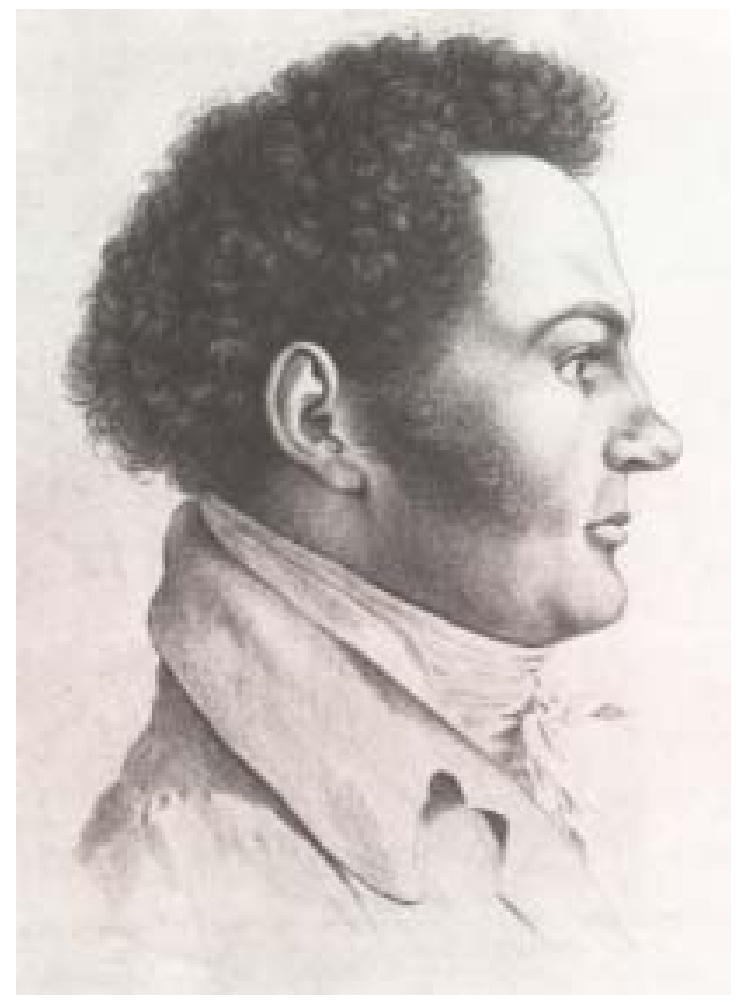

Fig. 1. Portrait of C.H. Pander (1817). Drawing made by d'Alton during their collaboration in Würzburg.

out Europe with d'Alton, in order to visit natural history museums and to observe the most remarkable skeletons of living and fossil species. Their efforts resulted in a monumental book, the Comparative Osteology, whose fourteen large format volumes appeared between 1821 and 1831 (Pander, 1821-1831). Each was devoted to the monograph of an animal or a taxon and was composed of a text written by Pander and plates engraved by d'Alton and his son Eduard (1803-1854).

On his return to Russia, in 1819, Pander took part as a naturalist in a diplomatic and military expedition in Boukhara, in Central Asia. In 1820, he became member of the Academy of Sciences of SaintPetersburg and devoted a great deal of effort to the work of this institution. He organized the Museum of Zoology and undertook many journeys in Russia to collect mineral, vegetal and animal samples. He explored especially the region of Saint Petersburg, where he described primary (Cambrian and Ordovician) formations (Pander, 1830). He left the Academy in 1827 for unknown reasons and returned to his familial property near Riga. Here, he divided his time between the management of his estate and his scientific work, which he slowly pursued, accumulating fossil samples of primary formations of the Baltic provinces collected on the occasion of his business trips. He came back to SaintPetersburg in 1842, as an official in the Mining Service. This position gave him the opportunity to acquire many samples from the whole Russian Empire. He was also able to take part in expeditions to Ural and Central Russia. Between 1856 to 1860 he published four monographs devoted to the study of different kinds of fossil fishes. The most interesting part of these books was the description of conodonts, minute fossilized structures he inter- preted as primitive vertebrate teeth. (There was a long-standing debate on the nature of conodonts; today the problem seems to be resolved and Pander's solution is now widely accepted). More generally he was a pioneer of the application of microscopic technology to fossils. He also attempted to reconstruct complete skeletons from fragments, applying Cuvier's method.

\section{Context: German embryology in the early 19th century}

In the early 19th century two kinds of embryological theories were in direct opposition (Rostand, 1930; Temkin, 1950; Needham, 1959; Roger, 1963; Adelmann, 1965-1966; Gould, 1977; Roe, 1981; Richards, 1992). According to the first, which we can call the theory of preformation (some historians prefer the term "preexistence" [Roger, 1963]), a complete embryo, with all parts of the adult, was already contained in the sperm ("animalculism") or, for most scientists, in the unfertilized egg ("ovism"). This small individual contained eggs (or sperms) with smaller beings, etc. Accordingly, all of mankind had been contained in Eve's ovaries ("emboîtement"). This theory had prevailed since the late 17th century for a variety of reasons. For one, it had the advantage of bypassing the difficult problem of the formation of such complex structures as organisms, since it claimed that the embryonic development was nothing but the growth of existing parts. But since the middle 18th century the rival theory of epigenesis had been gaining ground. The term had been coined by William Harvey (1578-1657) but the idea was very old: it was the conception that the individual was by no means preformed in the egg (or the sperm) but formed gradually from an initially unorganized matter. Ancient, especially Aristotelian embryology was largely epigenetic and this situation prevailed until the early 17 th century. But it depended on the Aristotelian physics and on the notion of final causes, which made it possible to explain the organization of matter during the development. The progressive collapse of this ancient physics led to a temporary decline of epigenesis, because the new mechanistic paradigm seemed to be unable to explain the formation of an individual from unorganized matter (Descartes own efforts were rapidly discredited) and many generations of scientists found the preformationist theory more satisfying. Nevertheless epigenesis retained some supporters, even in the early 18th century and it gathered a renewed favour in the second part of the century. In particular, Caspar Friedrich Wolff (1733-1794) played an important part in this evolution. In his Theoria generationis (1759) and De Formatione intestinorum (1768-1769), he argued that the embryo was built from a formless fluid and invoked the existence of an "essential force" ( vis essentialis) of a material nature that led to the organization of organic matter. His theory was based on very precise observations of the development of hen's egg and on a certain opposition against purely mechanistic views of ontogenesis. He was the first to glimpse the role of membrane folding in the formation of the organs of the foetus and for that reason he was sometimes considered as a forerunner of Pander and the germlayers theory. In fact there was no real germ-layer concept in his view, but the role he ascribed to embryonic membranes in the formation of organs (for example intestines) certainly influenced other embryologists. Although his books were reputed obscure, they were well known in the late 18th century, in particular as for the early developmental stages, the most difficult to observe but the most interesting in respect to the theory of generation and eminent 
scientists (e.g., the physiologist Johann Friedrich Blumenbach (1752-1840) and the philosopher and historian Johann Gottfried Herder (1744-1803) mentioned Wolff in their writings. It must be stressed that this kind of epigenesis was not the same as that of the earlier 18th century, for example Buffon's (Roe, 1981; Lenoir, 1982). Indeed, this new success of epigenesis came within the framework of the general progress of teleology in physiology at that time. Such scientists as Döllinger and Blumenbach had promoted the notion of Bildungstrieb ("formative drive") which, despite a certain variety of meanings, suggested that organic matter had a natural tendency towards self-organization under certain conditions, an idea which agreed with that of an epigenetic development of organisms. Blumenbach himself was a partisan of this conception and he played an important part in its spreading in Germany and in other countries. The theory of epigenesis was consequently more and more widely accepted in Germany in the late 18th century, not only among scientists, but also among philosophers like Kant or Schelling, so much so that, when Pander began his study, preformation already seemed to many outdated. He therefore began his study in a situation that was relatively favourable for epigenesis. There is no doubt that this context guided him in his observations and ensured in turn the success of his publications.

\section{Pander's embryological work and the theory of germ- layers}

Pander, Döllinger and d'Alton worked together relentlessly for many months. More than two thousand eggs were incubated between 35 and $40^{\circ} \mathrm{C}$, then opened and observed at every stage from the laying to the fifth day of incubation. The three men repeatedly compared their opinions and interpretations, so that they minimized the risk of error. They also called on other scientists, e.g. the botanist Christian Gottfried Daniel Nees von Esenbeck (1776-1858). Another important factor in their success was the experience Döllinger had acquired in removing and observing embryos. In particular, the technique (which required piercing the air chamber, in order to pull away the membranes from the shell and to prevent their tearing, as well as the isolation of the embryo and its observation on a black background), enabled them to describe the early development with an accuracy never achieved until then. Indeed, as we know today, development takes place at the surface of the yolk and, when the hen lays her egg, the developing embryo is a very thin and delicate membrane (Pander named it the "blastoderm") which may be injured when the shell is opened. According to Pander, his work was purely descriptive. He wrote: "Just as we refrained from any consideration on the comparison of the different organs, with respect to their period of development as well as to their mutual relations, we carefully avoided any judgment or conclusion that we could infer from the results of our research and which could lead to certain new theories" (Pander, 1817b: 30). But in fact the theoretical implications of this study were considerable. By the very fact that they confined themselves to the first five days of incubation (especially the first three, indeed), the authors revealed their particular interest in the most controversial period of embryonic development. Furthermore, their presentation of the developmental stages is meaningful: in contrast to their predecessors, including Wolff, they did not start describing already formed structures at late stages of ontogenesis in order to work backwards to the earliest develop- ment. They just presented what they observed at a certain point, without prejudging the fate of each part. The method employed for opening the egg and isolating the early embryo also reflected their goals. Indeed, Pander laid stress on the importance of the technique taught by Döllinger, which enabled him to preserve the thin membranes, whose role was of secondary importance for the preformationnists. Above all, the interpretation of certain embryonic structures revealed his unambiguous adherence to epigenesis. For example, in the yolk of the egg, whether it is fertilized or not, there is a clearer zone, just beneath the yolk membrane, which approximately corresponds to the position of the future embryo. Today this so-called "nucleus of Pander" (not a nucleus in the modern sense) is interpreted as a plug of whitish yolk, with no particular significance for development and whose function is purely a nutritive one, like the rest of the yolk. Nevertheless, it was a subject of debate for physiologists for many centuries and many supporters of preformation saw it as the germ of the fetus (Adelmann, 1965-1966: 1016-1030). One widely held idea was that the em-

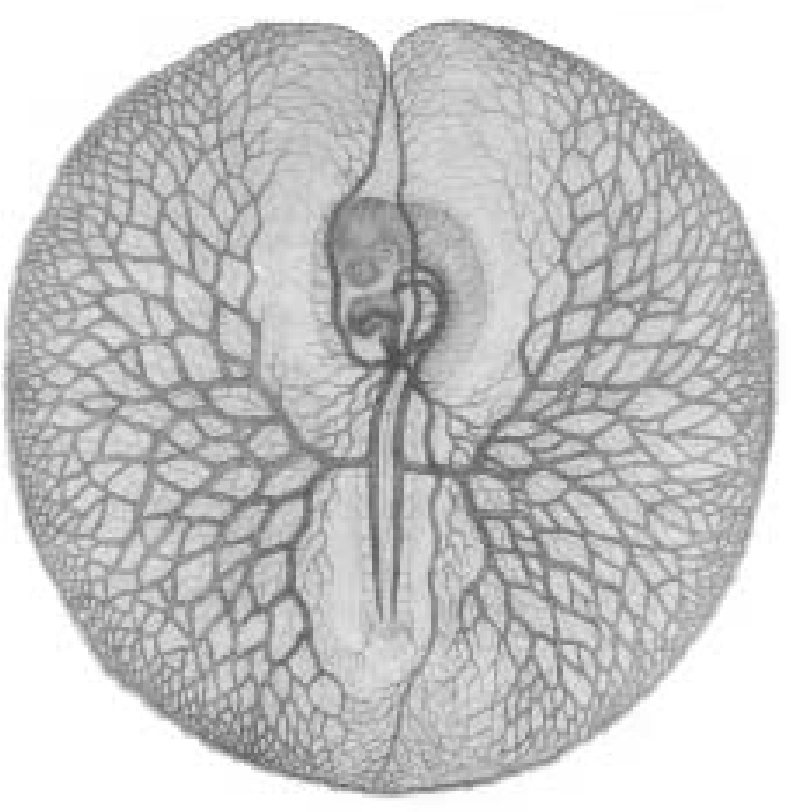

Fig. 2. A Pander perspective of the embryo. Drawing of a chick embryo showing the first circulation, by d'Alton (Pander 1817b, Plate VIII).

bryo, initially buried in the yolk, emerged from it in the course of development, so that it gave an impression of a gradual formation, although in fact it was present from the very beginning. As regards the membrane around the embryo, it was considered a kind of amnios, pushed away to the outside when the foetus grew. Wolff had already challenged this opinion. According to him, there was no embryo at all in the nucleus and the "amniotic" membrane did not exist in unfertilized eggs, they both appeared during the incubation. He thought that the embryo gradually formed beneath the membrane, which he called habitacula embryonis ("the residence of the embryo") (Wolff, 1768: 425).

In his own description of the egg at the beginning of incubation, Pander established that the "nucleus" existed in all eggs, fertilized or not and that it was a simple local differentiation of the yolk. He wrote: "The nucleus, which appears as a white mass, [...] partici- 
pates in the whole transformation of the yolk, loses its shape and gradually disappears around the seventh day [of incubation]" (Pander, 1818a: 514). On the other hand, the membrane only arises in fertilized eggs and is "a single layer, made up of the smallest granules visible with a lens and resembling a thin disc" (Pander, 1817a: 20). He added: "As for the membranous layer, it is of the highest importance during the chick's entire development. For the Embryo chooses this layer as its seat and domicile and, further, its substance also contributes greatly to the configuration of the chick, we shall therefore in the future call it the blastoderm " (Pander 1817a:21). Thus, Pander realized that the embryo is the membrane itself. This idea was probably the most daring one in his books and he emphasized it on many occasions. He said for example that the blastoderm had to be carefully isolated before observation, "since all transformations of the foetus arise in and by it" (Pander, 1817a: 14). Furthermore it is useless to use a highpower lens to observe the early stages, "for the blastoderm is still uniform in all the germ zone" (Pander, 1817b: 9).

The theoretical consequences are cautiously broached and Pander calls for Blumenbach's notion of Bildungstrieb: "With the formation of the blastoderm, the whole development of the chicken in the egg is founded and, from that time on, it progresses and concerns only this blastoderm; for every remarkable event that can happen afterwards must be considered nothing else but a metamorphosis of this membrane, which has an unending formative drive [Bildungstrieb] and of its layers. The life radiates from it in all directions and returns to it by concentrating itself!" (Pander, 1817b: $6)$. The blastoderm gradually increases in size and two zones differentiate: at the centre, a translucent or "pellucid" zone (area pellucida), already recognized by Wolff and around it an "opaque" zone (area opaca) which Pander is the first to name (Pander, 1817a: 24-25; 1817b: 7). The delamination of the blastoderm comes next, after twelve hours of incubation, resulting in the formation of two lamellae: the "mucous membrane" (or endoderm, in modern terminology) facing the yolk and the "serous membrane" (or ectoderm) facing the shell (Pander, 1817a: 27; 1817b: 5-6). Afterwards the serous membrane undergoes a new delamination and a third layer, the "vascular membrane" (or mesoderm) appears (Pander, 1817a: 33-34; 1817b: 11). Pander also introduced another important notion: folding, which made it possible to understand how the three-dimensional organism was formed from twodimensional layers. He stressed that this folding was not a passive phenomenon: for example, concerning the figures of the German edition, he wrote that they "do not represent dead membranes, whose folds, mechanically formed, would necessarily extend over the whole surface and would not be restricted to a given zone; such a view would inevitably lead to erroneous conceptions. The folds which cause the metamorphosis of the membranes have rather a spontaneous organic origin and they form at the proper place, whether it is by an expansion of the vesicles already existing or by the emergence of new vesicles, with no modification of the rest of the blastoderm" (Pander, 1817b: 40; see also Pander, 1818a:524). This text attests to Pander's epigenetic conception of the development: embryonic movements are initiated by active living matter, without the intervention of an external principle. This germ-layer theory had an important advantage for a supporter of epigenesis: because the early stages were extremely simple, i.e. single membranes, they confirmed both the absence of any preformed embryo in egg and the gradual formation of the animal. Furthermore, whereas many previous authors began by depicting each organ in its final and completed state, before studying its origin, Pander described the events chronologically and, in doing so, he emphasized that he did not defined the germ-layers by their fate. He wrote: "Actually, a particular metamorphosis begins in each of these three layers and each hurries towards its goal; only each one is not sufficiently independent by to represent by itself that for which it is destined; it still needs the help of its companions and therefore, although already designated for different ends, all three work collectively until each has reached an appropriate level" (Pander, 1817b: 12). This text certainly does not completely preclude germlayer specificity, but it underlines the fact that these membranes do not correspond rigorously to definite organs in the future embryo, they are only anatomical structures, with no pre-determinate functional specificity. Nonetheless, in a paper written in 1818, Pander returned to this question, acknowledging a certain kind of specificity of the germ-layers: "We have first to imagine clearly that the blastoderm consists of three different membranes intended for the development of the foetus: the inferior or mucous membrane deals with the formation of intestine, just as the vascular membrane contains the heart and the vessels and the serous membrane represents the covering of the spinal cord, the sides of the foetus and the amnios" (Pander, 1818a: 515). Paradoxically it is this oversimplification, probably dictated by the wish to be clearer, which had most influence on embryologists in the 19th century. It led to a certain return to preformation, since the germ-layers could be seen as predetermined. In that respect, von Baer's version of the germ-layer theory, for example, was less epigenetic than Pander's, since Baer assigned a more or less specific role to each layer (Balan, 1979: 248-249).

Pander's descriptions are in general more precise than those of his predecessors and less than von Baer's. We can mention some mistakes: the false interpretation of the chorda dorsalis, which he mistook for the spinal cord and of the somites, which he saw as vertebrae. He did not understand at all the formation of the neural tube and the role of the different germ-layers in the formation of the intestines and the extra-embryonic membranes. But all this is minor in comparison with the considerable advance caused by the introduction of the germ-layer theory.

Pander's work was well received in the scientific community (See, for example, Oken, 1817). Most reviewers emphasized its great quality and considered it the most important work in embryology since Wolff's, which it surpassed in clarity. However, some scientists had difficulty in understanding its most innovative aspects, in particular the significance of the blastoderm and the germlayers. Von Baer later confessed that he had not realized at once the consequences of his friend's writings and that these difficulties had led him to begin his own studies of chicken embryology in 1818, whose result was his epoch-making book, dedicated to Pander (Baer, 1828: vi; Baer, 1866: 292-297).

\section{The osteological work and the transformation of spe- cies}

Given his success, it might seem astonishing that Pander did not continue his embryological studies. Indeed, apart from some brief observations concerning the formation of the circulatory system in a note (Pander, 1818a), he completely gave up this field and turned to palaeontology and comparative anatomy (especially osteology). 
These sciences had been knowing a rapid development since the late eighteenth century and many scientists, such as Georges Cuvier, had established laws of reconstruction of entire fossil skeletons from few bones. In Germany, Goethe's osteological work appeared in 1817-1822 and had a lot of influence with new generations of naturalists who were trying to reveal the unity of the organic world.

It was therefore not astonishing that a young scientist like Pander showed an interest in comparative anatomy. Furthermore, this change of orientation was perfectly logical, as he explained himself in the first volume of his Comparative Osteology, devoted to the fossil Megatherium, an extinct giant sloth (Pander, 1821). During his stay in Madrid with d'Alton in 1818, he had observed the skeleton of this prehistoric animal which had been found not far from Buenos Aires in 1789 and which the viceroy had sent to Spain. This big animal had very massive bones, giving it a spectacular aspect. Pander first showed that the Spanish naturalists had made errors in reconstituting the complete skeleton. These mistakes had been spread by the figures published by Juan Bautista Bru (1740-1799). In particular, Cuvier had studied these illustrations and had coined the name "Megatherium" (it is still in use today, in accordance with the principle of priority). But Pander, on the basis of the comparison between the fossil and living species, established the correct disposition of the bones and d'Alton represented the animal in a more natural posture. This comparative method was justified, according to Pander, since he considered that this extinct species was closely related to living forms and that, despite many differences in size and appearance, the parts of the giant sloth and of his "issue" (Nachkommen) were "perfectly similar". He therefore suggested calling it Bradypus giganteus, using the genus name already given to living animals such as the American ai and he considered that it was possible to use the laws of comparative anatomy that had been established between living species. In turn, this study could throw light on the changes to which the species were subject in the course of Earth history. This view was, accordingly, truly transformist. Indeed, as early as 1818, Pander explicitly stated his aim: "We think that, by achieving our plan [the monograph of Bradypus giganteus ], not only have we brought an essential contribution to the precise study of animal world, but we have also established some new conceptions and ideas on the history of formation of new species" (Pander, 1818b: 1084). In the introduction of the monograph, Pander deplores the fact that the fossils are not sufficiently studied by comparative anatomists. He notices that their discovery is usually regarded as evidence of changes ("revolutions") on Earth, implying that the ancient fauna was very different from the current one. But afterwards, they are just used by geologists like minerals, to mark the different strata and their anatomical properties are generally neglected: "Hence, if these animal remains, which take their place in geology as mere objects, have not brought hitherto the same advantage in zoology and comparative anatomy, to which they really belong, this has to be ascribed to the received opinion that the living animal world is seen as a new creation, an opinion one found convenient to explain, or rather to leave unexplained, all the difference of forms" (Pander, 1821: 5). The catastrophist theory, which implies many creations ex nihilo, cannot account for either the diversity of forms and the similarities between living and extinct species. These affinities can only result from a common origin: "The difference of formation in fossil bones in comparison with those of still-living animals, which, according to the common observation, is greater the older the rock formation in which they are found (the animal remains quite similar to the living ones have been found only in the most recent strata), supports the assumption of an unbroken succession of descent [ununterbrochenen Folge der Abstammung] as well as the progressive transformation of animals [fortlaufende Verwandlung der Thiere] in relation to different external relationships. The observation that animals during the last millennia have reproduced with specific similarity in no way contradicts the opinion of a progressive metamorphosis [allmähligen Metamorphose], it must be viewed as a mere evidence that during this time no significant change in the external conditions of development has occurred; or it can be assumed that all forms of life today develop more slowly than in the primitive time" (Pander, 1821: 6). Many other passages of the Vergleichende Osteologie demonstrate Pander's transformism. According to him, 
the gradual transformation of organisms occurs under the influence of material factors, especially of the changes in their external conditions. Pander stresses on this point on many occasions. An entire chapter of the volume devoted to rodents is entitled: "General remarks on the external influences on the organic development of animals" (Pander, 1824). To support this theory, he uses the appearance of hereditary variations after some generations in certain domestic animals when they are introduced in different climates (Pander, 1821: 16). This primordial importance of the environmental conditions for any morphological change, combined with the narrow geographical localization of the "catastrophes" as revealed by geology, invalidates the hypothesis of many creations separated by worldwide catastrophes: "Life appears in nature as the first internal principle of any existence, only as a community which is bound for its whole duration to identical conditions. By simple and sufficient consequences, the conditions of an animal creation were present only once and the perpetuation of animals must be conceived in an unbroken series: since there is no reason to consider general and simultaneous the revolutions which took place on the surface and on which we base the frequent extinction of the animal world, insofar as clear traces show rather that the submersion of inhabited regions occurred only in places, powerfully, suddenly and mostly in one direction" (Pander, 1821: 5). According to Pander, there are many "external conditions" involved in the transformation of species, but one of the most important is the source of food. Indeed, the function of nutrition represents a connection between organisms and their environment, it is both a factor of unity among the different animals and a factor of change in case of variations of the milieu (Pander, 1824: 1-6; also in facsimile in Raikov, 1984: 35-43).

This constant reference to the importance of environmental conditions cannot fail to remind us of Lamarck. Indeed, there are several other common issues, for example the effect of use and non-use which, according to Pander, has led to the fusion or the degeneration of certain bones in current sloth. It is difficult to know if and to which extent Pander was influenced by the French naturalist. Lamarck's work might have been known by some people in Germany, at any rate his transformist views were in no way marginal in Europe at that time, even if some scientific circles and institutions were hostile to them (Corsi, 2001). Furthermore, Pander may have become acquainted with Lamarck's books during his travel in Western Europe. In any case, although he never quoted him, it is likely that he knew his reflections, directly or indirectly and that he was inspired by them.

\section{Adapting Goethe's metamorphosis}

For Pander, the demonstration of transformism was not an end in itself. The variation of species was only an aspect of a far more general natural law, which also governed the development of the hen's egg. In order to identify this fundamental principle, he appealed to Goethe's morphological thought, in particular to the notion of metamorphosis. Goethe had introduced this concept in order to demonstrate the essential identity of all floral organs (Goethe, 1987; see Richards, 2002; Schmitt, 2001): according to him, leaves, sepals, petals, stamens and carpels were all derived from a same primitive organ. He had extended this idea to animals and argued, for example, that the cranial bones were "metamorphosed" vertebrae. For him, those transformations were not real ones: metamorphosis had to be seen as an ideal process. But Goethe himself had generalized this concept and related it to metamorphosis in the usual sense (for example the transformation of caterpillars into butterflies). These phenomena were all, according to him, expressions of the same essential process, but in the case of insects, the transformation was visible ("successive metamorphosis") whereas that of vertebrae occurred at once ("simultaneous metamorphosis").

Pander already knew Goethe's theory when he began his study on development and the term "metamorphosis" appears in his dissertation's title as well as in the German text. There is no doubt that this word was connected to Goethe's name and work, since d'Alton personally knew the poet. In his Comparative Osteology, Pander referred to Goethe's morphological work on several occasions and he saw metamorphosis as the most important innovation in comparative anatomy and physiology. He applied this concept to the animal development: "In the History of the development of chicken in egg, [...] we clearly recognized and revealed, by the formation of the membranes, the metamorphosis of simple forms into the most diverse systems of the organism" (Pander, 1821: 5). As for the transformation of species, it is seen as another expression of the same phenomenon, on a larger scale: "Every mutual comparison of the animals or their parts can, now, be conceived in connection with the idea of a metamorphosis; similarly, the order in which this comparison must be made can only be determined from it" (Pander, 1821: 6). Therefore, animal diversity results from a metamorphosis which arises in response to variations of the milieu. Indeed, the modifications especially concern the most external parts of organisms, those which are the most exposed to the variations of the milieu: "As a representation of a first general developmental form, all animals have an identical structure in their different parts; this similarity is greater if one considers the animal internally. This metamorphosis to the outside [Metamorphose nach aussen] is revealed for example by the limbs of the quadrupeds, which always begin with simple and identical segments, however different they are at the end by number and form" (Pander, 1821: 6).

Pander also borrows from Goethe the idea of different kinds of metamorphosis and he introduces them into palaeontology. According to him, a simultaneous metamorphosis occurred at the beginning of the world, giving birth to a number of living forms. Then, a progressive metamorphosis acted on these primitive forms, depending on the variations of the external conditions, but these transformations were only superficial: "The diversity of animals in consequence of a metamorphosis must be considered an original and simultaneous diversity, a different quantitative relation, or a progressive diversity, depending on the qualitative relations with the environment. The existence of the second kind of metamorphosis explains the degeneration of animals in different climates after many generations and the existence of the original type shows the permanence of these animals in a continuously similar form for several generations after the return in their original conditions; the coexistence of the two kinds seems to be the result of an elementary process" (Pander, 1821: 5-6). Then comparative anatomy aims to recognize the initial differences and the secondary changes.

Thus metamorphosis gives us keys to understanding the deep similarity between all living beings, because it shows how the same undifferentiated matter can give rise to different forms, on the scale 
of an individual (embryogenesis) as well as of nature as a whole (appearance and gradual transformation of species). It enables us to represent the animal kingdom as a homogeneous whole, in accordance with Döllinger's as well as Goethe's or Schelling's teaching. In that respect, the transformation of species is understood as the gradual "development" of the living world, the "world organism" (Weltorganismus), subordinated to the conditions of the milieu. This influence of the environment is, indeed, an aspect of the general unity of nature and it ensures the close relation between the whole and the different parts. Every living being is "an image of the common world organism"; the earth itself is a part of this global organism, animals and plants were born and have developed on it like on a maternal breast: so it is natural that there is an interdependency (Pander, 1824: 1-6).

This issue of unity of world, of a constantly evolving global organism, expresses the influence of Schelling's Naturphilosophie. To this philosophic movement, Pander also borrows the notion of a mutual action of polarized "forces" (represented, for example, by the magnetic phenomena) which constantly tend to neutralize each other. According to Schelling, this is the cause of all movements and all changes and the naturalist may see in it the origin of the development of an organism as well as of a species. Such a constructive opposition of forces can produce the different creature of the world, which are only temporary stages of a general process of transformation into higher and higher forms.

Pander identifies this process with Goethe's metamorphosis and he links it together with his own conceptions on the role of external conditions, which are in constant conflict with the ability of living beings to react against them. New forms arise from this opposition between an individual and his milieu. In a same animal, antagonisms also appear between the different systems, in particular between the muscular and osseous system, resulting in the formation of nervous structures, the highest and the most representative of the essence of the animal.

The process described by Schelling has an ideal meaning: the different living forms represent stages of the general elevation of organic matter, but it is not very clear whether Schelling thinks of a real, physical transformation of species in the course of generations. At any rate, these conceptions have undoubtedly favoured the subsequent diffusion of the transformist theory. But in 1820, few naturalists were explicitly transformist and it is often difficult to say if they believed in evolution or not. As for Pander, he developed in that respect much more concrete ideas than Schelling or Oken and this historical reality of the transformation of species depends, according to him, on the material influence of external conditions. Indeed, like Döllinger, Pander saw scientific activity as more concrete than did many Naturphilosophen. General or abstract considerations are relatively rare in his works, apart from those of the Vergleichende Osteologie. Then, all natural laws were interpreted as physical, material ones and the transformation of living forms was seen as a real one.

In that respect, epigenetic embryology gave a very concrete representation of the dynamism of living matter which could apply both to species and to individuals. Furthermore, the gradual development observed during ontogenesis was the only period of the life of an organism during which a deep modification of its form could occur, in relation with external actions. Then, epigenesis gave not only a positive representation of the general process of metamorphosis, but it made materially possible the application of this process to the succession of generations. This application was difficult to imagine in the context of preformationist theories, since an already formed individual could hardly modify its whole morphology.

The Vergleichende Osteologie was well received. Goethe wrote a very favourable appreciation in his Morphologie (Goethe, 1987 [1822]: 545-551), so that the book was well-known in the nineteenth century and many authors like Darwin mentioned it as late as the end of the century.

\section{Conclusion}

Pander's work clearly shows that the demonstration of epigenesis in embryology represented an important factor in the elaboration and diffusion of transformist theories, first, because it made possible a transformation of species in response to external causes during ontogenesis and then, because it offered a concrete representation of transforming matter tending to higher forms. Given the philosophical and cultural context at that time (at least in Germany) and the success of such ideas as correspondence between organism and universe, it seems inevitable that this view would lead to the hypothesis of a general transformation of the living world.

\section{Acknowledgements}

I wish to express my sincere thanks to Professor Evelyn Fox Keller, Doctors Kai Torsten Kanz and Michaël Manuel for their advice and their help in writing this paper.

\section{References}

ADELMANN, H. (1965-1966) Marcello Malpighi and the evolution of embryology. 5 vols. Cornell University Press, Ithaca.

D'ALTON, E. (1811-1816). Naturgeschichte des Pferdes, 2 vols., Weimar.

BAER, K.E. VON (1828-1837), ÜberEntwicklungsgeschichte der Thiere. Beobachtung und Reflexion. 2 vols. Bornträger, Königsberg.

BAER, K.E. VON (1866), Nachrichten über Leben und Schriften, Schmitzdorff, St. Petersburg.

BALAN, B. (1979), L'ordre et le temps. L'anatomie comparée et l'histoire des vivants au XIXe siècle. Vrin, Paris.

BULlOUGH, V. B. (1974). Pander, Christian Heinrich. In Dictionary of Scientific Biography (Ed. C.C. Gillispie), Scribner's Sons, New York, vol. 10, pp. 286-288.

CHURCHILL, F. B. (1991) The Rise of Classical Descriptive Embryology. In $A$ Conceptual History of Modern Embryology (Ed. S.F. Gilbert), Plenum, New York, pp. 1-29.

CORSI, P. (2001). Lamarck. Genèse et enjeux du transformisme, 1770-1830. Editions du CNRS, Paris.

GOETHE, J.W. VON (1987). Schriften zur Morphologie (Ed. D. Kuhn). Deutscher Klassiker Verlag, Frankfurt.

GOULD, S.J. (1977). Ontogeny and Phylogeny. Harvard University Press, Cambridge.

KNORRE, H. VON (1973). 17 Briefe von Christian Heinrich Pander (1794-1865) an Karl Ernst von Baer (1792-1876). Giessener Abhandlungen zur Agrar- und Wirtschaftsforschung des Europäischen Ostens. 59: 89-116.

LENOIR, T. (1982). Strategy of life. Teleology and mechanics in nineteenth century German biology. Reidel, Dordrecht.

MIKHAILOV, A.T. (1997), Epigenesis versus preformation: first chapter of the Russian embryological research. Int. J. Dev. Biol. 41: 755-762.

NEEDHAM, J. (1959). A History of Embryology. 2nd ed. Cambridge University Press, Cambridge.

OKEN, L. (1817). Dissertatio inauguralis. Auctore Chr. Pander. Isis, oder enzyklopädische Zeitung von Oken 1: 1529-1540. 


\section{S. Schmitt}

PANDER, C.H. (1817a). Dissertatio inauguralis sistens historiam metamorphoseos, quam ovum incubatum prioribus quinque diebus subit, Nitribitt, Würzburg.

PANDER, C.H. (1817b). Beiträge zur Entwicklungsgeschichte des Hühnchens im Eye, Brönner, Würzburg.

PANDER, C.H. (1818a). Entwickelung des Küchels. Isis, oder enzyklopädische Zeitung von Oken 2: 512-524.

PANDER, C.H. (1818b). Riesenfaulthier (Megatherium). Isis, oder enzyklopädische Zeitung von Oken 2: 1083-1086.

PANDER, C.H. (1821). Dievergleichende Osteologie. 1. Das Riesenfaulthier, Bradypus giganteus, beschrieben, und mit den verwandten Geschlechtern verglichen. Weber, Bonn.

PANDER, C.H. (1824). Die vergleichende Osteologie. 6. Die Skelete der Nagethiere. Weber, Bonn.

PANDER, C.H. (1830). Beyträge zur Geognosie des russischen Reiches. Kray, St Petersburg.

PANDER, C.H. (2003). Les textes embryologiques de C.H. Pander(1794-1865). Ed. and trad. by S. Schmitt. Brepols, Turnhout.

RAIKOV, B.E. (1951). Russkie biologi-evoliutsionistydo Darvina, Moscow/Leningrad, Press of Academy of Sciences of U.S.S.R.

RAIKOV, B.E. (1984). Christian Heinrich Pander. Ein bedeutender Biologe und Evolutionist. An important biologist and evolutionist 1794-1865. German Translation with Commentary and English Summaries by W.E. von Hertzeberg and P.H. von Bitter. Verlag Waldemar Kramer, Frankfurt am Main.

RICHARDS, R.J. (1992). The Meaning of Evolution. The morphological construction and ideological reconstruction of Darwin's theory. University of Chicago Press, Chicago.
RICHARDS, R.J. (2002). The Romantic Conception of Life. Science and philosophy in the age of Goethe, University of Chicago Press, Chicago.

ROE, S. (1981). Matter, life and generation; 18th-Century Embryology and the HallerWolff Debate. Cambridge University Press, Cambridge.

ROGER, J. (1963). Les Sciences de la vie dans la pensée française du XVIIle siècle, Paris, Armand Colin.

ROSTAND, J. (1930). La Formation de l'être. Histoire des idées sur la génération. Hachette, Paris.

SCHMITT, S. (2001). Type et métamorphose dans la morphologie de Goethe, entre Classicisme et Romantisme. Revue d'Histoire des Sciences 54: 495-522.

TEMKIN, O. (1950). German concepts of ontogeny and history around 1800. Bulletin of the History of Medicin 24: 227-246.

WOLFF, C.F. (1759). Theoria generationis. Hendel, Halle.

WOLFF, C.F. (1768-1769). De formatione intestinorum praecipue, tum et de amnio spurio, aliisque partibus embryonis gallinacei, nondum visis. Novi Commentarii Academiae Scientiarum Imperialis Petropolitanae 12: 403-507 and 13: 478-530. Translated into French and edited by M. Perrin and J.C. Dupont (2003), Caspar Friedrich Wolff. De formatione intestinorum. De la formation des intestins (17681769). Turnhout, Brepols.

Received: 0 ctober 2004

Reviewed by R eferees: N ovember 2004 M odified by Authors and Accepted for Publication: December 2004 